\title{
THROMBIN FORMATION. I. THE ROLE OF CALCIUM, SERUM AC-GLOBULIN AND TISSUE THROMBOPLASTIN ${ }^{1}$
}

\author{
By JESSICA H. LEWIS ${ }^{2}$ AND J. H. FERGUSON \\ (From the Department of Physiology, University of North Carolina, Chapel Hill, and the \\ Department of Medicine, Duke Medical School, Durham)
}

(Received for publication July 19, 1948)

Recent investigations have shown that thrombin is not formed simply by the interaction of prothrombin and thromboplastin in the presence of calcium ion but that another factor ( $s$ ) is important and perhaps necessary. Almost simultaneously various workers have described new factors but the different investigational approaches involved have made it difficult to determine if all factors discussed are identical.

Quick (1-3) has described a labile factor disappearing from plasma on storage, but differing from the classical prothrombin. Owren (4-6) reported a new factor, "factor V," which he found diminished in one patient and which he describes as "found in normal plasma, thermolabile, and important to thrombin formation." He expresses its action by the following outline :

Prothrombin (?) +Factor V $\stackrel{\text { Thrombokinase+Ca++ }}{\longrightarrow}$ Factor VI Prothrombin $\stackrel{\text { Factor VI+Ca++ }}{\longrightarrow}$ Thrombin

Ware, Guest, and Seegers $(7,8)$ and Ware, Murphy and Seegers (9) have isolated from plasma and from serum two factors, called Acglobulin, which they believe accelerate the activation of purified prothrombin in the following fashion:

Prothrombin +Thromboplastin $\stackrel{\mathrm{Ca}^{++}}{\longrightarrow}$ Thrombin

Plasma Ac-globulin $\stackrel{\text { Thrombin }}{\longrightarrow}$ Serum Ac-globulin

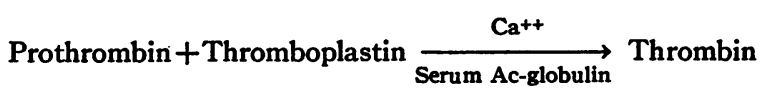

Fantl and Nance (10-12) and Munro and Munro (13) have also reported the presence of clot acceleratory substance $(s)$ in prothrombin free plasma.

We have been fortunate in obtaining specimens

1 This investigation was supported in part by a research grant from the Division of Research Grants and Fellowships of the National Institute of Health, U. S. Public Health Service.

2 Postdoctorate Fellow, U. S. Public Health Service. of Dr. Seeger's purified prothrombin and serum Ac-globulin and have designed these experiments to study the formation of thrombin in the presence of these purified reagents. One of us (14) has recently reported extensively on the formation of thrombin from a purified prothrombin product. This work was completed before the identification of Ac-globulin and must now be modified to include this factor.

\section{MATERIALS}

Borate buffer (buff.) : $\mathrm{pH}=7.7$ viz. 45 volumes $2.5 \%$ $\mathrm{H}_{3} \mathrm{BO}_{3}, 45$ volumes $0.5 \% \mathrm{NaCl}, 10$ volumes $4 \% \mathrm{Na}_{2} \mathrm{~B}_{4} \mathrm{O}_{7}$. $12 \mathrm{H}_{2} \mathrm{O}$. Used as a solvent and diluent throughout.

Prothrombin (Pro) : $0.1 \%$ solution of prothrombin 3 prepared from bovine plasma. Lot no. 480414.

Serum accelerator globulin ( $A c G): 0.1 \%$ solution of $\mathrm{AcG}^{3}$ prepared from bovine serum. Lot no. 480205 .

Tissue thrombloplastin (Tpln) : prepared from acetone dried human brain. $0.5 \mathrm{gm}$. dried brain suspended in $\mathbf{5 0}$ cc. buffer, stirred at $37^{\circ}$ for 10 minutes, and centrifuged rapidly for 10 minutes. The supernatant, an active thromboplastin containing small amounts of prothrombin and Ac-globulin, was discarded and the precipitate again suspended in $50 \mathrm{cc}$. buffer, stirred at $37^{\circ}$ for 10 minutes and recentrifuged. The opalescent supernatant proves an extremely active thromboplastin almost completely free of prothrombin and Ac-globulin.

Prothrombin, Ac-globulin and thromboplastin were prepared in large lots, divided into daily requirements and stored frozen at $-20^{\circ} \mathrm{C}$.

Thrombin: Lot no. $480310^{3}$ prepared as noted in text.

Fibrinogen (B.F.) : $5 \mathrm{gm}$. of bovine fibrinogen (Armour) were dissolved in $500 \mathrm{cc}$. of buffer. To this $170 \mathrm{cc}$. of saturated ammonium sulfate solution were added, the precipitate collected by centrifugation, washed with onefourth saturated ammonium sulfate, then quickly with cold distilled water to remove traces of ammonium sulfate, and finally redissolved in $500 \mathrm{cc}$. of buffer. It was divided into daily requirements and stored frozen at $-20^{\circ} \mathrm{C}$.

\section{METHODS}

Thrombic mixtures ( $T$ ) were prepared from the stated reagents to a volume of $5 \mathrm{cc}$. with buffer. At stated

${ }^{3}$ Obtained through kindness of Dr. W. H. Seegers, Wayne University. 


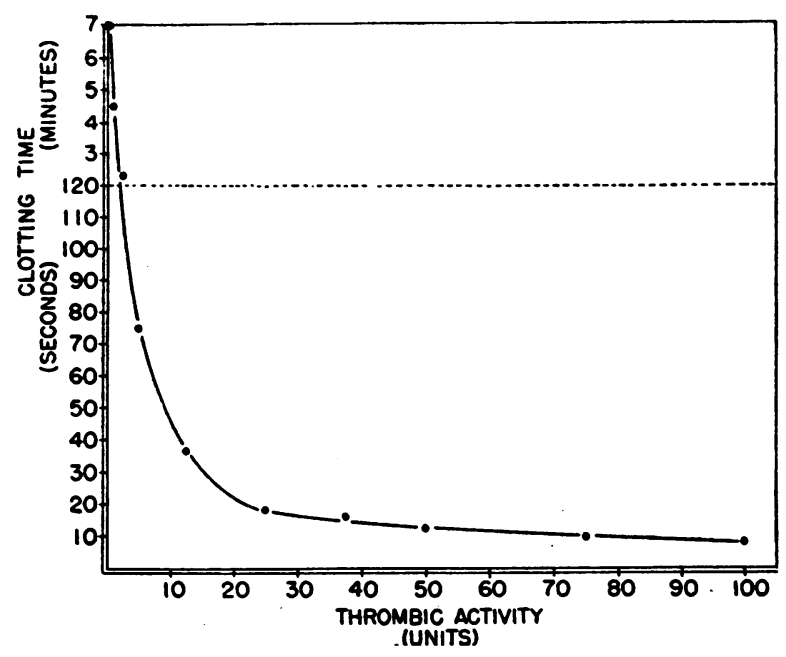

Fig. 1. Clotting Times of Dilutions of Standard Thrombic Mixture: $100 \%=100$ Units

incubation periods, $0.25 \mathrm{cc}$. thrombic mixture was added to $0.5 \mathrm{cc}$. of fibrinogen and clotting time recorded. All procedures were performed at $28^{\circ} \mathrm{C}$. unless otherwise stated. Following the first 24 -hour incubation period all thrombic mixtures were followed at daily intervals until no evidence of further activation remained and thrombin had started to deteriorate.

To facilitate interpretation of results thrombic activity is presented as a "unit" value. One hundred units (in a volume of $0.25 \mathrm{cc}$.) of thrombin will clot the standard fibrinogen in 7.5 seconds. This value was chosen as it represents the clotting time obtained when $0.25 \mathrm{cc}$. of the standard thrombic mixture at full activation is added to $0.5 \mathrm{cc}$. fibrinogen. The standard thrombic mixture consists of $0.1 \mathrm{cc}$. of $0.1 \%$ prothrombin, $0.1 \mathrm{cc}$. of $0.1 \%$ Ac-globulin, $0.5 \mathrm{cc}$. thromboplastin in a volume of $5 \mathrm{cc}$. with $\mathrm{CaCl}_{2}$ added to a final concentration of $0.03 \mathrm{M}$. Dilutions of this mixture were rapidly prepared in $0.03 \mathrm{M}$ $\mathrm{Ca}$-buffer. Figure 1 shows these values plotted as clot-

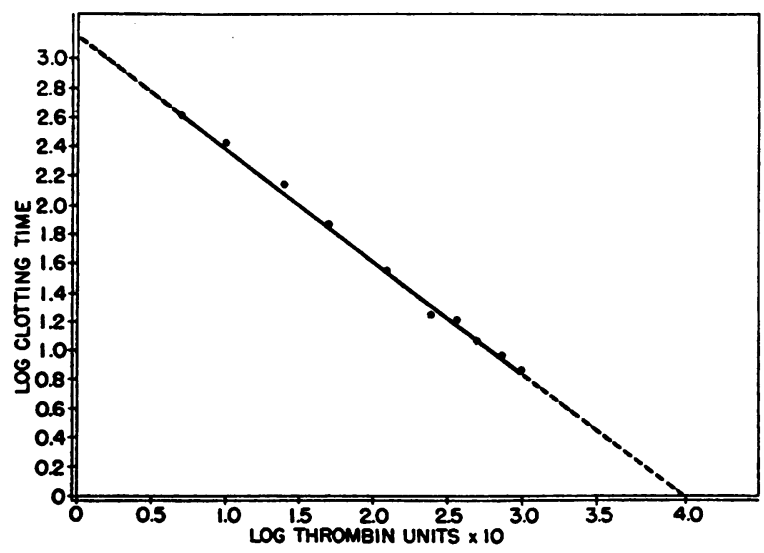

Fig. 2. Logarithm of Clotting Time Plotted Against LogarithM OF UNITS OF ThROMBIN $\times 10$ ting times against percentage thrombin. In Figure 2 are plotted the logarithms of the clotting times against the logarithms of the per cent thrombin $\times 10$. This gives a straight line which was interpolated to obtain values above 100. Values of less than 0.5 unit (C.T. = seven minutes) are grouped together as there is a little significance to minor variations in this range.

\section{Controls:}

\section{RESULTS}

Table I presents the control results for this series of experiments. Obviously, none of these materials are completely pure. The fibrinogen itself

TABLE I

\section{Control results}

Units of thrombin formed from thrombic mixture containing stated amounts of reagents in $5 \mathrm{cc}$.

\begin{tabular}{|c|c|c|c|c|c|c|c|c|c|c|c|}
\hline \multirow[b]{2}{*}{$\mathbf{T}$} & \multicolumn{4}{|c|}{ Reagents* } & \multicolumn{7}{|c|}{ Incubation period } \\
\hline & $\mathrm{Ca}$ & Pro & AcG & Tpln & min. & $\begin{array}{c}15 \\
\text { min. }\end{array}$ & $\begin{array}{c}30 \\
\text { min. }\end{array}$ & $\begin{array}{c}60 \\
\text { min. }\end{array}$ & $\begin{array}{c}4 \\
\text { hr. }\end{array}$ & $\begin{array}{l}24 \\
\text { hr. }\end{array}$ & $\begin{array}{l}72 \\
\text { hr. }\end{array}$ \\
\hline $\begin{array}{l}1 \\
2 \\
3 \\
4\end{array}$ & .03 & 0.1 & 0.1 & 0.5 & $\begin{array}{l}0.5 \\
0 \\
0.5 \\
0\end{array}$ & $\begin{array}{l}- \\
0 \\
0.5 \\
0\end{array}$ & $\begin{array}{l}-\overline{0} \\
0.5 \\
0\end{array}$ & \begin{tabular}{|l|}
0.5 \\
0 \\
0.5 \\
0
\end{tabular} & $\begin{array}{l}- \\
0 \\
0.5 \\
0\end{array}$ & $\begin{array}{l}\overline{0} \\
0 \\
0\end{array}$ & $\begin{array}{l}- \\
0 \\
0 \\
0\end{array}$ \\
\hline $\begin{array}{l}5 \\
6 \\
7\end{array}$ & $\begin{array}{l}.03 \\
.03 \\
.03\end{array}$ & 0.1 & 0.1 & 0.5 & $\begin{array}{l}0.5 \\
0.5 \\
0.5\end{array}$ & - & $\begin{array}{l}0.5 \\
0.5 \\
0.5\end{array}$ & $\begin{array}{l}0.5 \\
0.5 \\
0.5\end{array}$ & $\begin{array}{l}0.5 \\
0.5 \\
0.5\end{array}$ & $\begin{array}{l}0.5 \\
0.5 \\
0.5\end{array}$ & $\begin{array}{l}0.5 \\
0.5 \\
0.5\end{array}$ \\
\hline $\begin{array}{r}8 \\
9 \\
10 \\
11\end{array}$ & $\begin{array}{l}.03 \\
.03 \\
.03 \\
.03\end{array}$ & $\begin{array}{l}0.1 \\
0.1 \\
0.1\end{array} \mid$ & $\begin{array}{l}0.1 \\
0.1 \\
0.1\end{array}$ & $\begin{array}{l}0.5 \\
0.5 \\
0.5\end{array}$ & $\begin{array}{c}0.6 \\
0.5 \\
1.5 \\
30\end{array}$ & $\begin{array}{r}0.6 \\
1.0 \\
3.5 \\
67\end{array}$ & \begin{tabular}{|r|}
0.6 \\
1.5 \\
4.5 \\
89
\end{tabular} & \begin{tabular}{|c|}
0.6 \\
2.4 \\
4.5 \\
100
\end{tabular} & \begin{tabular}{|l|}
0.8 \\
8.0 \\
5.0 \\
100
\end{tabular} & \begin{tabular}{|c}
0.6 \\
8.0 \\
5.0 \\
84
\end{tabular} & $\begin{array}{r}0.5 \\
13.0 \\
4.5 \\
70\end{array}$ \\
\hline
\end{tabular}

* Ca expressed as final molarity; other reagents in cc. of stock solution.

contains all the essential elements for coagulation except calcium and clots slowly (trace clot in one hour) on recalcification. This is enhanced slightly by addition of prothrombin, Ac-globulin or thromboplastin, but there is no evidence that these mixtures form thrombin themselves as there is no increase in thrombic activity during a 72-hour incubation period. This is likewise true of mixture 8 , $\mathrm{Ca}+$ prothrombin + Ac-globulin. In contrast to this both mixtures 9 and 10 show thrombin formation suggesting (1) that either prothrombin or Ac-globulin is capable of producing thrombin, or (2) that these substances contain impurities. This problem is investigated in a later section.

\section{Calcium effects:}

Figure 3 presents the maximal thrombin yields of the same amounts of prothrombin, Ac-globulin and 


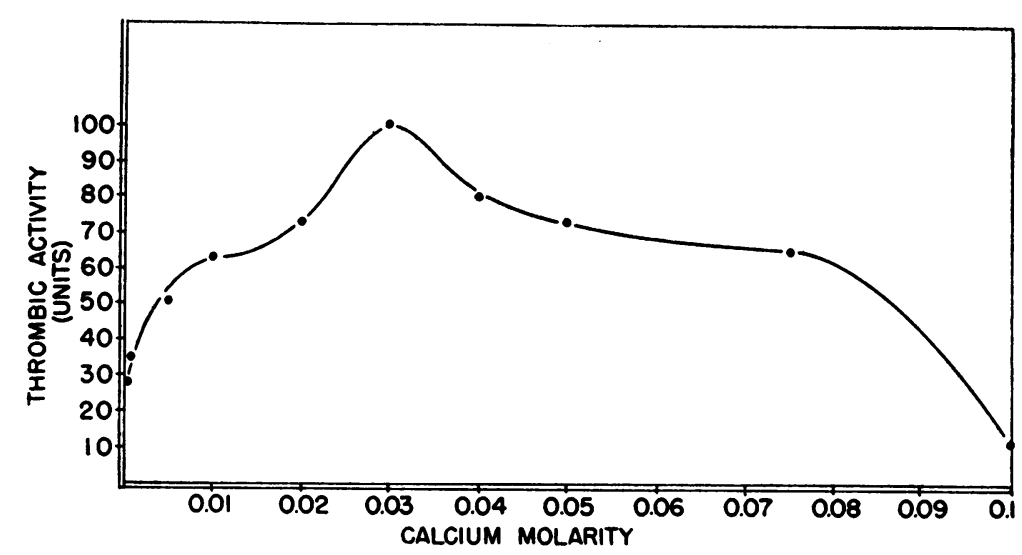

Fig. 3. Maximal Thrombin Formation at Various Calcium Concentrations (Pro, AcG and Tpln Constant)

TABLE II

Effect of calcium concentration

Units thrombin formed from thrombic mixtures containing 0.1 cc. $0.1 \%$ Pro, 0.1 cc. $0.1 \%$ AcG, 0.5 cc. Tpln in 5 cc. buffer at stated $\mathrm{Ca}$ concentrations.

\begin{tabular}{l|c|c|c|c|c|c|c||c|c}
\hline \hline & \multicolumn{7}{c}{$\begin{array}{c}\text { Calcium } \\
\text { molarity }\end{array}$} & \multicolumn{7}{|c}{ Incubation period } \\
\cline { 2 - 8 } & $\begin{array}{c}5 \\
\text { min. }\end{array}$ & $\begin{array}{c}15 \\
\text { min. }\end{array}$ & $\begin{array}{c}30 \\
\text { min. }\end{array}$ & $\begin{array}{c}45 \\
\text { min. }\end{array}$ & $\begin{array}{c}60 \\
\text { min. }\end{array}$ & $\begin{array}{c}4 \\
\text { hr. }\end{array}$ & $\begin{array}{c}24 \\
\text { hr. }\end{array}$ & $\begin{array}{c}48 \\
\text { hr. }\end{array}$ & $\begin{array}{c}96 \\
\text { hr. }\end{array}$ \\
\hline .0005 & 5.6 & 28 & 27 & 26 & 25 & 25 & 20 & 18 & 13 \\
.001 & 18 & 35 & 35 & 35 & 30 & 28 & 28 & 27 & 16 \\
.005 & 43 & 51 & 50 & 48 & 50 & 50 & 50 & 48 & 30 \\
.01 & 51 & 63 & 61 & 58 & 58 & 58 & 52 & 51 & 34 \\
.02 & 64 & 73 & 71 & 71 & 73 & 73 & 71 & 63 & 45 \\
.03 & 30 & 67 & 89 & 100 & 100 & 100 & 84 & 80 & 51 \\
.04 & 15 & 55 & 69 & 71 & 73 & 73 & 80 & 76 & 53 \\
.05 & 7.5 & 29 & 53 & 60 & 61 & 62 & 69 & 73 & 54 \\
.075 & 5 & 18 & 46 & 54 & 57 & 60 & 63 & 65 & 50 \\
.1 & 0.6 & 0.9 & 1.1 & 1.5 & 2.5 & 4 & 10 & 11 & 11 \\
\hline
\end{tabular}

thromboplastin in various $\mathrm{Ca}$ concentrations. The optimum $\mathrm{Ca}$ is a final concentration of $0.03 \mathrm{M}$.

Inspection of the raw data in Table II reveals that maximal thrombin formation is rapid in $\mathrm{Ca}$ concentration of 0.0005 to $0.02 \mathrm{M}$ and thrombin yield increases with increasing $\mathrm{Ca}$ concentration. At $0.03 \mathrm{M}$ the rate of thrombin production is somewhat slower, the maximum being reached at 45 minutes. Above this the rates are still slower and the final yield decreases as the $\mathrm{Ca}$ concentration increases.

An explanation for this inhibitory effect of high Ca concentration was sought. Table III shows that the major effect occurs in thrombin production and not in conversion of fibrinogen to fibrin.

Table IV shows that adjustment of the $\mathrm{pH}$ does not affect the $\mathrm{Ca}$ inhibitory effect.
TABLE III

$\begin{array}{cc}\begin{array}{c}\text { Effects of Ca concentration on conversion of } \\ \text { fibrinogen to fibrin }\end{array} \\ \text { Calcium molarity } & \text { Clotting time (seconds) } \\ 0.0 & 8 \\ 0.001 & 9 \\ 0.01 & 9 \\ 0.03 & 8.5 \\ 0.1 & 8\end{array}$

0.25 cc. of purified thrombin $(.001 \%)$ in various $\mathrm{Ca}$ concentrations was added to $0.5 \mathrm{cc}$. B.F.

Table $\mathrm{V}$ shows that increasing the ionic strength (as crudely measured by specific resistance) of $0.01 \mathrm{M} \mathrm{Ca}$ to that of $0.1 \mathrm{M} \mathrm{Ca}$ by addition of a neutral salt greatly slows the rate of thrombin formation but does not completely account for the $\mathrm{Ca}$ inhibitory effect.

We also wished to determine whether the calcium optimum varied with the prothrombin or Acglobulin content. Thrombic mixtures containing prothrombin $0.01 \mathrm{cc}$. and prothrombin $0.5 \mathrm{cc}$., with Ac-globulin and thromboplastin constant at 0.1 and $0.5 \mathrm{cc}$. respectively, were prepared with various concentrations of $\mathrm{Ca}$ and the optimum in each case

TABLE IV

Effect of adjustment of $p H$ on thrombin formation in high calcium concentrations

\begin{tabular}{l|c|c|c|c|c|c}
\hline \hline \multirow{2}{*}{$\begin{array}{c}\text { Calcium } \\
\text { molarity }\end{array}$} & $\mathrm{pH}$ & \multicolumn{5}{|c}{ Incubation period (minutes) } \\
\cline { 3 - 7 } & & 5 & 15 & 30 & 60 & 240 \\
\hline 0.03 & 7.4 & 30 & 67 & 89 & 100 & 100 \\
0.1 & 7.15 & 0.6 & 0.9 & 1.1 & 2.5 & 4.0 \\
$0.1^{*}$ & 7.45 & 1.0 & 1.0 & 1.1 & 1.5 & 3.0 \\
\hline
\end{tabular}

* Adjusted with $1 \mathrm{M} \mathrm{NaOH}$. 
was found to be $0.03 \mathrm{M} \mathrm{Ca}$. Thrombic mixtures containing $0.005,0.01,0.05$, and $0.5 \mathrm{cc}$. of Ac-globulin with prothrombin and thromboplastin constant at 0.1 and $0.5 \mathrm{cc}$., respectively, were prepared. The Ac-globulin concentrations of 0.05 and $0.5 \mathrm{cc}$. reached maximal thrombic activity in $\mathrm{Ca}$ concentration of $0.03 \mathrm{M}$. In the lower Ac-globulin concentrations the $\mathrm{Ca}$ concentration had less effect, maximal yields being obtained in $\mathrm{Ca}$ ranges of 0.01 to $0.03 \mathrm{M}$ with a more rapid thrombin formation in the lower $\mathrm{Ca}$ concentration.

\section{Effects of Ac-globulin:}

Figure 4 shows the effects of increasing concentrations of Ac-globulin. Both the rate of thrombin formation and the final thrombin yield were increased by increasing concentrations of Acglobulin in thrombic mixtures containing constant prothrombin, thromboplastin and $\mathrm{Ca}$ content. No optimum Ac-globulin concentration was obtained above which additional thrombin was not formed.

TABLE V

Effect of adjustment of specific resistance on thrombin formation

\begin{tabular}{l|c|c|c|c|c|c|c}
\hline \hline $\begin{array}{c}\text { Calcium } \\
\text { molarity }\end{array}$ & $\begin{array}{c}\text { Specific } \\
\text { resist- } \\
\text { ance }\end{array}$ & \multicolumn{6}{|c}{ Incubation period } \\
\cline { 3 - 7 } & & $5 \mathrm{~min}$. & $15 \mathrm{~min}$. & $30 \mathrm{~min}$ & $60 \mathrm{~min}$. & $4 \mathrm{hr}$. & $24 \mathrm{hr}$. \\
\hline 0.1 & 40 & 0.6 & 0.9 & 1.1 & 2.5 & 4.0 & 10 \\
0.01 & 128 & 51 & 63 & 61 & 58 & 58 & 52 \\
$0.01^{*}$ & 37.2 & 1.0 & 2.0 & 11 & 20 & 25 & 30 \\
\hline
\end{tabular}

* Adjusted by addition of solid $\mathrm{NaCl}$.
As the Ac-globulin alone forms about 5 units of thrombin from each $0.1 \mathrm{cc}$., at least this increase in thrombin production would be expected, as the Ac-globulin concentration is increased.

Thrombic mixture 9 (Table I), prothrombin + thromboplastin $+\mathrm{Ca}$, showed the slow formation of 13 units of thrombin in 72 hours; longer incubation did not increase the yield. This suggested either that Ac-globulin was not necessary to thrombin formation or that the prothrombin or thromboplastin might contain Ac-globulin. Further purification was attempted by heating these substances. Table VI shows that both the thromboplastin and prothrombin lose some of their potentialities by heating in a boiling waterbath. The boiled thromboplastin and fresh prothrombin still form 6.0 units of thrombin. If the prothrombin is also boiled no appreciable thrombin is formed unless Ac-globulin is added. From this we must con-

TABLE VI

Effect of heat treatment on removal of AcG from Pro and $T$ pln

\begin{tabular}{|c|c|c|c|c|c|c|c|c|c|c|c|}
\hline \multicolumn{5}{|c|}{ Reagents } & \multicolumn{7}{|c|}{ Incubation period } \\
\hline Pro & $\begin{array}{c}\text { Pro } \\
\text { II }\end{array}$ & Tpln & $\operatorname{Tpln}_{\text {II }}$ & AcG & $\underset{\mathrm{min}}{5}$ & $\underset{\mathrm{min}}{15}$ & $\begin{array}{c}30 \\
\min .\end{array}$ & $\begin{array}{c}60 \\
\min \end{array}$ & $\begin{array}{c}4 \\
\text { hr. }\end{array}$ & $\begin{array}{l}24 \\
\text { hr. }\end{array}$ & $\begin{array}{l}72 \\
\text { hr. }\end{array}$ \\
\hline $\begin{array}{l}0.1 \\
0.1 \\
0.1 \\
0.1\end{array}$ & $\begin{array}{l}0.1 \\
0.1\end{array}$ & $\begin{array}{l}0.1 \\
0.1\end{array}$ & $\begin{array}{l}0.1 \\
0.1 \\
0.1 \\
0.1\end{array}$ & $\begin{array}{l}0.1 \\
0.1 \\
0.1\end{array}$ & \begin{tabular}{|c|}
30 \\
0.5 \\
22 \\
0.5 \\
1.0 \\
0.5
\end{tabular} & $\begin{array}{c}67 \\
1.0 \\
63 \\
0.5 \\
2.5 \\
0.5\end{array}$ & $\begin{array}{c}89 \\
1.5 \\
69 \\
0.5 \\
8.0 \\
0.5\end{array}$ & \begin{tabular}{|c}
100 \\
2.4 \\
84 \\
1.5 \\
8.0 \\
0.5
\end{tabular} & \begin{tabular}{|c|}
100 \\
8.0 \\
80 \\
3.0 \\
14.0 \\
0.5
\end{tabular} & $\begin{array}{r}84 \\
8.0 \\
75 \\
6.0 \\
22.0 \\
0.5\end{array}$ & \begin{tabular}{|l}
70 \\
13.0 \\
70 \\
6.0 \\
16.0 \\
0.5
\end{tabular} \\
\hline
\end{tabular}

Pro $\mathrm{I}=$ untreated, Pro $\mathrm{II}=100^{\circ} \mathrm{C}$. for seven minutes, Tpln I $=$ untreated, Tpln II $=100^{\circ} \mathrm{C}$. for seven minutes. $.03 \mathrm{M} \mathrm{Ca}$ throughout.

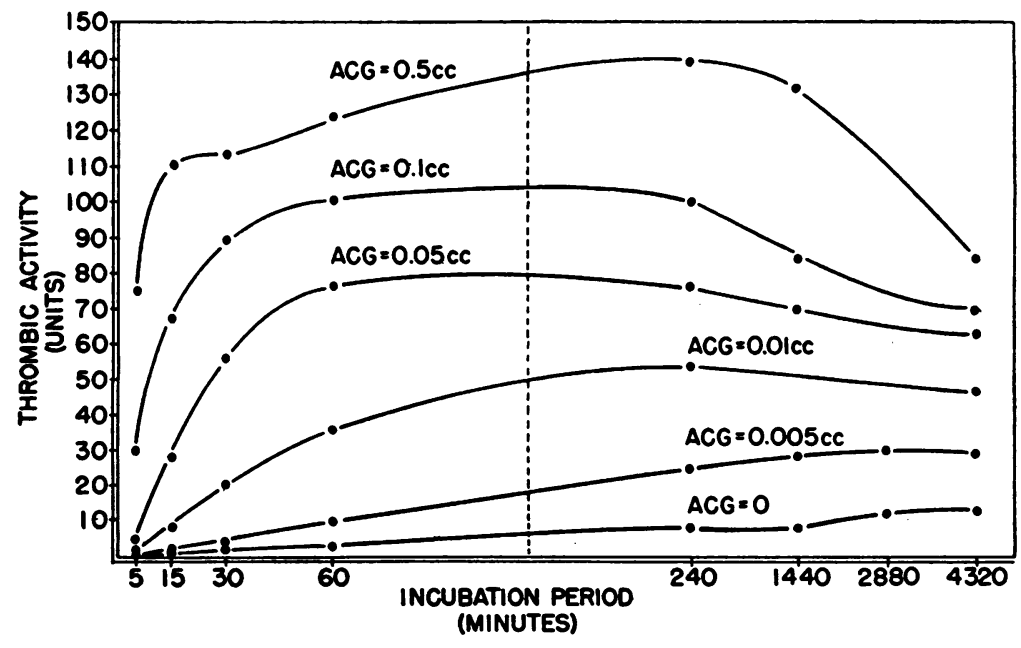

Fig. 4. Effects of Varying Quantities of AcG (Pro, Tpln and Ca Constant) 
TABLE VII

Effect of $\mathrm{BaSO}_{1}$ treatment on $\mathrm{AcG}$

\begin{tabular}{l|c|c|c|c|c|c|c|c}
\hline \multicolumn{2}{c|}{ Reagents } & \multicolumn{5}{c}{ Incubation period } \\
\hline Pro & AcG & AcG(BaSO.) & $5 \mathrm{~min}$. & $15 \mathrm{~min}$. & $30 \mathrm{~min}$ & $60 \mathrm{~min}$. & $4 \mathrm{hr}$. & $48 \mathrm{hr}$. \\
\hline 0.1 & 0.1 & & 30 & 67 & 89 & 100 & 100 & 80 \\
0.1 & & 0.1 & 0.8 & 2.0 & 5.0 & 10.5 & 21 & 15 \\
& 0.1 & & 1.5 & 3.5 & 4.5 & 4.5 & 5.0 & 5.0 \\
& & 0.1 & 0.5 & 0.5 & 0.5 & 0.5 & 0.5 & 0.5 \\
\hline
\end{tabular}

All thrombic mixtures contain $\mathrm{Ca} \quad .03 \mathrm{M}$ and $\mathrm{Tpln}$ $0.5 \mathrm{cc}$.

clude that both prothrombin and thromboplastin contain traces of Ac-globulin which can only be removed by drastic treatment which also destroys some of their thrombin-forming ability.

Thrombic mixture 10 of the control series showed some thrombin formation from Ac-globulin without the addition of prothrombin. This suggested that Ac-globulin contained traces of prothrombin. In order to prove this we incubated the Ac-globulin with $1 / 5$ volume of $35 \%$ barium sulfate suspension for 10 minutes, removed the precipitate by centrifugation and tested it as shown in Table VII. No thrombin was formed in the prothrombin-free mixture but although much of the Ac-globulin activity was lost by barium sulfate treatment, enough remains to form some thrombin when prothrombin is added.

\section{Effects of thromboplastin:}

Figure 5 shows the effects of varying quantities of tissue thromboplastin on thrombin formation from fixed quantities of prothrombin, Ac-globulin and $\mathrm{Ca}$. No thrombin is formed in the absence of thromboplastin. As the concentration of thromboplastin increases the rate of thrombin formation

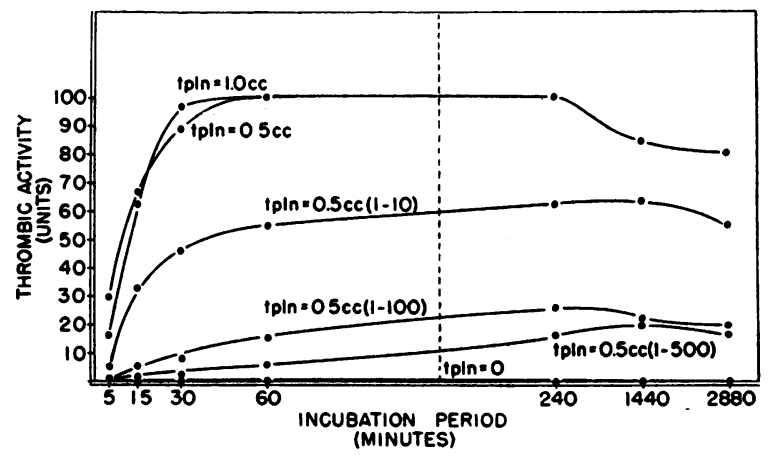

Fig. 5. EFfects of Varying Quantities of TPLN (Pro, AcG and Ca Constant) and yield of thrombin are increased to a maximal point above which no effect is noted on further increase of thromboplastin.

\section{Effects of prothrombin:}

Table VIII shows the effects of varying prothrombin concentration in mixtures containing standard amounts of Ac-globulin and thromboplastin. Unit values over 100 are calculated from Figure 2. When $1 / 10$ volume of prothrombin is used, roughly one-tenth the amount of thrombin is formed. When five-fold volume is used, roughly five times the amount of thrombin is formed.

TABLE VIII

Effect of varying Pro concentration

Units thrombin formed from thrombic mixtures containing $0.1 \mathrm{cc} .0 .1 \% \mathrm{AcG}, 0.5 \mathrm{cc}$. Tpln, and stated amounts of Pro in 5 cc. $0.03 \mathrm{M} \mathrm{Ca-buffer}$

\begin{tabular}{l|c|c|c|c|c|c|c}
\hline \hline \multirow{7}{*}{$\begin{array}{c}\text { Pro } \\
c c .\end{array}$} & \multicolumn{6}{|c}{ Incubation period } \\
\cline { 2 - 7 } & $5 \mathrm{~min}$. & $15 \mathrm{~min}$. & $30 \mathrm{~min}$. & $60 \mathrm{~min}$. & $4 \mathrm{hr}$. & $24 \mathrm{hr}$. & $72 \mathrm{hr}$. \\
\hline 0.01 & 8.7 & 11.5 & 11.5 & 11.5 & 11.5 & 12.4 & 11.8 \\
0.10 & 30 & 67 & 89 & 100 & 100 & 100 & 70 \\
0.50 & 38 & 403 & 553 & 600 & 634 & 634 & 496 \\
\hline
\end{tabular}

\section{DISCUSSION}

An artificial system of purified reagents has been set up to study the formation of thrombin. Data obtained suggest that four substances-prothrombin, serum Ac-globulin, thromboplastin and calcium ions-are necessary for thrombin formation and that the yield of thrombin depends upon the proportions of these substances.

Inspection of our data reveals that thrombin, even that formed from these purified reagents, deteriorates rather rapidly. It is always possible that significant deterioration of thrombin has occurred before full activation in the slower thrombic mixtures.

If we again review our data in light of these considerations, we note that the rate of thrombin formation is rapid in calcium concentrations of 0.0005 to $0.02 \mathrm{M}$, that thrombin yield increases with increase of $\mathrm{Ca}$, and that each of these mixtures loses about 10 units of activity in the ensuing 48 hours. It is difficult to conclude otherwise than that thrombin yield is directly dependent upon calcium concentration, although calcium optimum apparently varies little or not at all with prothrombin or Ac- 
globulin content. The inhibitory effects of high calcium concentrations were in part explained as general effects of high salt concentration.

We were rather surprised to find our calcium optimum so much higher than that of other investigators $(15,16)$. This can in part be explained by the frequent use by many investigators of a onestage prothrombin determination in which rate of thrombin formation is determined rather than the final yield of thrombin. Before determining the calcium optimum for this system, exactly similar preliminary experiments were performed at $0.0025 \mathrm{M} \mathrm{Ca}$. The results obtained showed similar trends although the thrombin yields were somewhat lower. There is no evidence that the high $\mathrm{Ca}$ optimum is dependent upon excessive amounts of citrate or oxalate in these preparations. As far as we are aware there are only traces of these substances present.

Ac-globulin has been shown to increase both the rate of formation and yield of thrombin from a given amount of prothrombin, thromboplastin and Ca. In fact, our results indicate that Ac-globulin is necessary for the formation of any thrombin, but in order to demonstrate this we employed drastic methods (boiling) which destroyed a great deal of the prothrombin itself. We also tried heating at various temperatures below boiling but usually obtained prothrombin preparations in which some activation occurred without added Ac-globulin.

The Ac-globulin itself was noted to produce some thrombin when activated with thromboplastin and $\mathrm{Ca}$. We attempted to remove the prothrombin from Ac-globulin by adsorption onto barium sulfate. In this way we were able to obtain an Acglobulin which was completely free of prothrombin, but in the process we lost most of the Ac-globulin property.

Thromboplastin was found to exert effects similar to Ac-globulin and Ca. Without tissue thromboplastin no thrombin was formed. As the concentration of thromboplastin increased the rate and yield of thrombin increased until a maximal amount was reached. Above this no effect was noted. These experiments have all employed thromboplastin derived from tissue. As this seems somewhat unphysiological, work is now in progress to study the effects of platelets and plasma thromboplastic substance.
Variations in prothrombin concentration produced marked changes in thrombin yield. When the prothrombin was reduced to $1 / 10$ the concentration of the standard mixture, and the Ac-globulin and thromboplastin maintained constant, thrombin was formed rapidly and about $1 / 10$ the final yield of thrombin was obtained. On the other hand, when the prothrombin was increased to five times the original concentration, thrombin was formed more slowly, complete activation occurring at four hours. The final calculated thrombin yield was somewhat greater than five times the standard yield.

From the experiments presented in this paper we are unable to formulate any absolute conception of the mechanism of blood coagulation. If it is assumed, as Seegers has done, that factor VI and serum Ac-globulin are identical, we are unable to confirm Owren's hypothesis that factor VI directly converts prothrombin to thrombin. If we then turn to Seegers' theory of thrombin formation we are forced to disagree in that we find serum Acglobulin is necessary for prothrombin conversion, and our data indicate that thromboplastin, calcium, Ac-globulin, and prothrombin react together in such a fashion that the quantity of thrombin formed is dependent upon the quantity of each in the original mixture. We have as yet been unable to study the role of plasma Ac-globulin in this reaction. Previous reports (16) from this laboratory have suggested the formation of a thrombin "intermediary." How this hypothesis will be affected by the new factor, Ac-globulin, cannot be decided until more is known of the nature of this reaction.

\section{CONCLUSIONS}

From the data presented in this paper we conclude that four substances are necessary for thrombin formation:

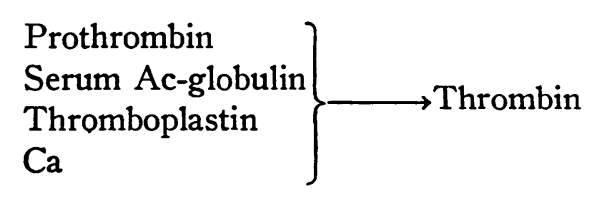

None of these may be omitted, but we have not studied the substitution of other materials for these specific substances, i.e., strontium for calcium, etc. The exact mechanism of interaction of these substances is not absolutely ascertained, but it appears 
that the thrombin yield, as well as the formation rate, is dependent on the quantity of each.

\section{BIBLIOGRAPHY}

1. Quick, A. J., On the constitution of prothrombin. Am. J. Physiol., 1943, 140, 212.

2. Quick, A. J., The components of prothrombin. Proc. Soc. Exper. Biol. \& Med., 1946, 62, 249.

3. Quick, A. J., Congenital hypoprothrombinemia and pseudo-hypoprothrombinemia. Lancet, 1947, ii, 379.

4. Owren, P. A., The Coagulation of Blood. Oslo, 1947.

5. Owren, P. A., Parahemophilia. Lancet, 1947, i, 446.

6. Owren, P. A., New factors concerned in the coagulation of blood. Bull. Schweiz. Akad. Med. Wiss., 1947-8, 3, 163.

7. Ware, A. G., Guest, M. M., and Seegers, W. H., A factor in plasma which accelerates the activation of prothrombin. J. Biol. Chem., 1947, 169, 231.

8. Ware, A. G., Guest, M. M., and Seegers, W. H., Plasma accelerator factor and purified prothrombin activation. Science, 1947, 106, 41.
9. Ware, A. G., Murphy, R. C., and Seegers, W. H., The function of Ac-globulin in blood clotting. Science, 1947, 106, 618.

10. Fantl, P., and Nance, M., Acceleration of thrombin formation by a plasma component. Nature, 1946, $158,708$.

11. Fantl, P., and Nance, M., Activation of prothrombin. Australian J. Science, 1946, 9, 117.

12. Fantl, P., and Nance, M., The physiological activation of prothrombin. M. J. Australia, 1948, I, 128.

13. Munro, M. P., and Munro, F. L., The reversible inactivation of prothrombin: A factor responsible for its partial reactivation. Am. J. Physiol., 1947, $150,409$.

14. Ferguson, J. H., The activation of prothrombin. Blood, in press.

15. Quick, A. J., On the quantitative relationship between calcium and prothrombin. Am. J. Physiol., 1947, 148, 211.

16. Ferguson, J. H., Quantitative relationships of calcium and cephalin in experimental thrombin formation. Am. J. Physiol., 1938, 123, 341. 